\title{
A survey of IgA protease production among clinical isolates of Proteeae
}

\author{
B. W. SENIOR, MERETE ALBRECHTSEN* and M. A. KERR*
}

Departments of Medical Microbiology and Pathology, Dundee Univerșity Medical School, Ninewells Hospital, Dundee DD1 9SY

\begin{abstract}
Summary. A collection of 100 strains of Proteeae, in which all species within the tribe were represented, was examined for $\operatorname{IgA}$ protease production. The strains were isolated from various clinical specimens from sick and healthy persons in several countries. IgA protease-producing strains were not found amongst species of Providencia and Morganella but were common in Proteus spp. All the strains of $P$. mirabilis and $P$. penneri and many of the strains of $P$. vulgaris examined produced an EDTA-sensitive protease that cleaved the IgA heavy chain outside the hinge region. The proteus enzyme was different in this respect from the EDTA-sensitive, hingecutting proteases of other bacteria. The ability to produce IgA protease was unrelated to the $\mathrm{O}$ antigenicity, biotype or bacteriocin type of the strain. $\operatorname{IgA}$ protease production may be an important virulence mechanism for Proteus strains.
\end{abstract}

\section{Introduction}

Immunoglobulin A (IgA) in the form of secretory IgA, is the predominant immunoglobulin in mucous secretions. Its function is to protect mucous membranes and underlying tissue from damage by micro-organisms or their products. The function of serum IgA, which differs from the secreted form in being monomeric and lacking the secretory component, is less clear. It is believed to have a role in the regulation of the inflammatory response and in the disposal of antigens from the circulation. Of the many bacteria examined, only a few produce extracellular enzymes capable of degrading IgA (IgA proteases) (Kilian et al., 1983a). These include major pathogens such as Neisseria gonorrhoeae, $N$. meningitidis, Haemophilus influenzae, Streptococcus pneumoniae and bacteria associated with periodontal disease and dental plaque formation (Plaut $e t$ al., 1974, 1975; Blake and Swanson, 1978; Kilian et al., 1979, 1983b; Male, 1979; Mulks et al., $1980 a, b$; Kilian, 1981; Kilian and Holmgren, 1981); because other species of these genera, nonpathogenic for normal individuals, do not form $\operatorname{IgA}$ proteases, the production of these enzymes may be associated with virulence (Mulks and Plaut, 1978). IgA proteases act by cleaving the heavy chain of the human $\operatorname{IgAl}$ isotype at specific sites within a 16-amino acid proline-rich polypeptide in the hinge

Received 12 Feb. 1987; accepted 4 May 1987. region. This sequence is not present in $\operatorname{IgA} 2$ which is, therefore, resistant to IgA protease cleavage (Plaut et al., 1974, 1975; Kilian et al., 1980; Mulks et al., 1980b).

Among the Proteeae, strains of Proteus spp., particularly $P$. mirabilis, are a common cause of chronic and recurrent urinary-tract infection and have been found more frequently than Escherichia coli in urinary-tract infections of the elderly (Senior, 1979) and young boys (Bergström, 1972; Hallet et al., 1976; Khan et al., 1978). Furthermore, the consequences of infection with Proteus spp. are often more serious because, whereas $E$. coli is usually confined to the bladder, Proteus strains have a special predilection for the upper urinary tract (Fairley et al., 1971) where they may cause damage to the renal tubular epithelium (Braude et al., 1960) and bring about conditions leading to the formation of renal stones (Griffith et al., 1973). On the other hand, Morganella morgani and Providencia spp. are uncommonly associated with urinary-tract infections (Senior, 1979) but are more frequently associated with diarrhoea (Senior and Leslie, 1986). These differences arise through the operation of different pathogenic mechanisms in the different genera.

We have recently shown that $P$. mirabilis strains of diverse type, isolated from many different clinical situations, produce IgA protease. The enzyme from $P$. mirabilis strains, however, differed from that of other pathogenic bacteria by cleaving the $\operatorname{IgA}$ 
heavy chain outside the hinge region (Senior et al., 1987). This present investigation sought to determine whether, among the Proteeae, IgA protease formation was restricted to $P$. mirabilis.

\section{Materials and methods}

\section{Bacterial strains}

A series of 100 strains presumed to belong to the tribe Proteeae was isolated in pure cultures from clinical specimens of unrelated individuals and stored on nutrientagar slopes in screw-capped bottles at $4^{\circ} \mathrm{C}$. Most strains $(83 \%)$ were isolated from patients resident in five British cities and the remainder $(17 \%)$ were from patients in Canada, Germany, Hungary, Sweden and Turkey. The strains of $S$. pneumoniae and $N$. gonorrhoeae used for comparison were originally isolated from clinical specimens but had been maintained for several months by repeated subculture on heated-blood agar and modified New York City medium, respectively.

\section{Media}

Nutrient broth was Nutrient Broth No. 2 (Oxoid CM 67 ), $2.5 \% \mathrm{w} / \mathrm{v}$ in distilled water. Nutrient agar (Oxoid CM3) and blood agar (BA) made up from Columbia Agar Base (Oxoid CM 331) with sterile horse blood (Oxoid SR 50) $5 \% \mathrm{v} / \mathrm{v}$ were prepared and sterilised according to the manufacturer's instructions. Heated-blood agar (HBA) was heated BA. Modified New York City medium (MNYC) was prepared according to the method of Young (1978) but with horse blood (Oxoid SR 50). Tryptophan deaminase agar (TDA), urea-indole medium, ornithine decarboxylase $-\mathrm{H}_{2} \mathrm{~S}$ medium and peptone-water sugar media were prepared and sterilised as previously described (Senior and Leslie, 1986).

\section{Identification of strains}

A nutrient-broth culture of each strain was inoculated as a spot on to a TDA plate and into urea-indole medium and mannose peptone water. After overnight incubation at $37^{\circ} \mathrm{C}$, strains which formed tryptophan deaminase (Senior and Leslie, 1986) and urease but failed to form acid from mannose were identified as Proteus spp. Those which formed tryptophan deaminase and acid from mannose were identified as species of either Morganella or Providencia. Each strain was then speciated by its reaction in appropriate tests for the genus as shown in the table.

\section{Bacteriocin typing of strains}

Strains of Proteus spp. were typed for their ability to produce (P) bacteriocins (proticines) and for their sensitivity (S) to proticines- $\mathrm{P} / \mathrm{S}$ typing--according to the method of Senior (1977) and Senior and Larsson
(1983). $M$. morgani strains were similarly typed for bacteriocin (morganocin) production and sensitivity (Senior, 1987).

\section{Preparation of ${ }^{125}$ I-labelled $\operatorname{Ig} A$}

IgA was purified from normal human plasma as previously described (Senior et al., 1987). The resulting pure $\operatorname{IgA}$ was labelled with ${ }^{125} \mathrm{I}$ by the chloramine-T method of Hunter and Greenwood (1962).

\section{Preparation of $\operatorname{Ig} A$ protease}

Each strain was grown on dialysis-tubing membrane covering the surface of culture media plates-BA for Proteeae, HBA for $S$. pneumoniae and MNYC for $N$. gonorrhoeae. The membrane and bacteria were subsequently washed in $5 \mathrm{~mm}$ Tris buffer $(p \mathrm{H} \mathrm{7.2)}$ and the supernate used as a source of IgA protease as previously described (Senior et al., 1987).

\section{Polyacrylamide gel electrophoresis and autoradiography}

Purified ${ }^{125}$ I-labelled IgA was digested with protease and the products of digestion analysed by SDS discontinuous gel electrophoresis on 5-22\% gradient polyacrylamide gels and subsequent autoradiography according to methods previously described (Senior et al., 1987).

\section{Results}

\section{IgA protease production by $P$. mirabilis strains}

A collection of $15 P$. mirabilis strains of 14 distinct $\mathrm{P} / \mathrm{S}$ types and at least $7 \mathrm{O}$-antigenic types was examined for $\operatorname{IgA}$ protease production. The strains included isolates from urine, faeces, sputum, renal and ureteric stones, and a brain abscess, from patients and from healthy individuals. Each strain produced IgA protease.

\section{IgA protease production by $P$. vulgaris strains}

A series of 24 strains of $P$. vulgaris of 15 different $\mathrm{P} / \mathrm{S}$ types, 14 of biotype 2 and 10 of biotype 3 , was examined. The strains were isolated from urine, faeces, a leg ulcer, a groin abscess, an infected ear and an infected burn. Only $12(50 \%)$ of the strains $-11(79 \%)$ of the biotype- 2 strains and $1(10 \%)$ of the biotype- 3 strains-produced IgA protease. There was no obvious association between protease production and source, biotype or $\mathrm{P} / \mathrm{S}$ type of the strain. IgA protease producing and non-producing strains were found amongst those with the same biotype and $\mathrm{P} / \mathrm{S}$ type. The low proportion of $\operatorname{IgA}$ 
Table. The biochemical reactions of members of the tribe Proteeae

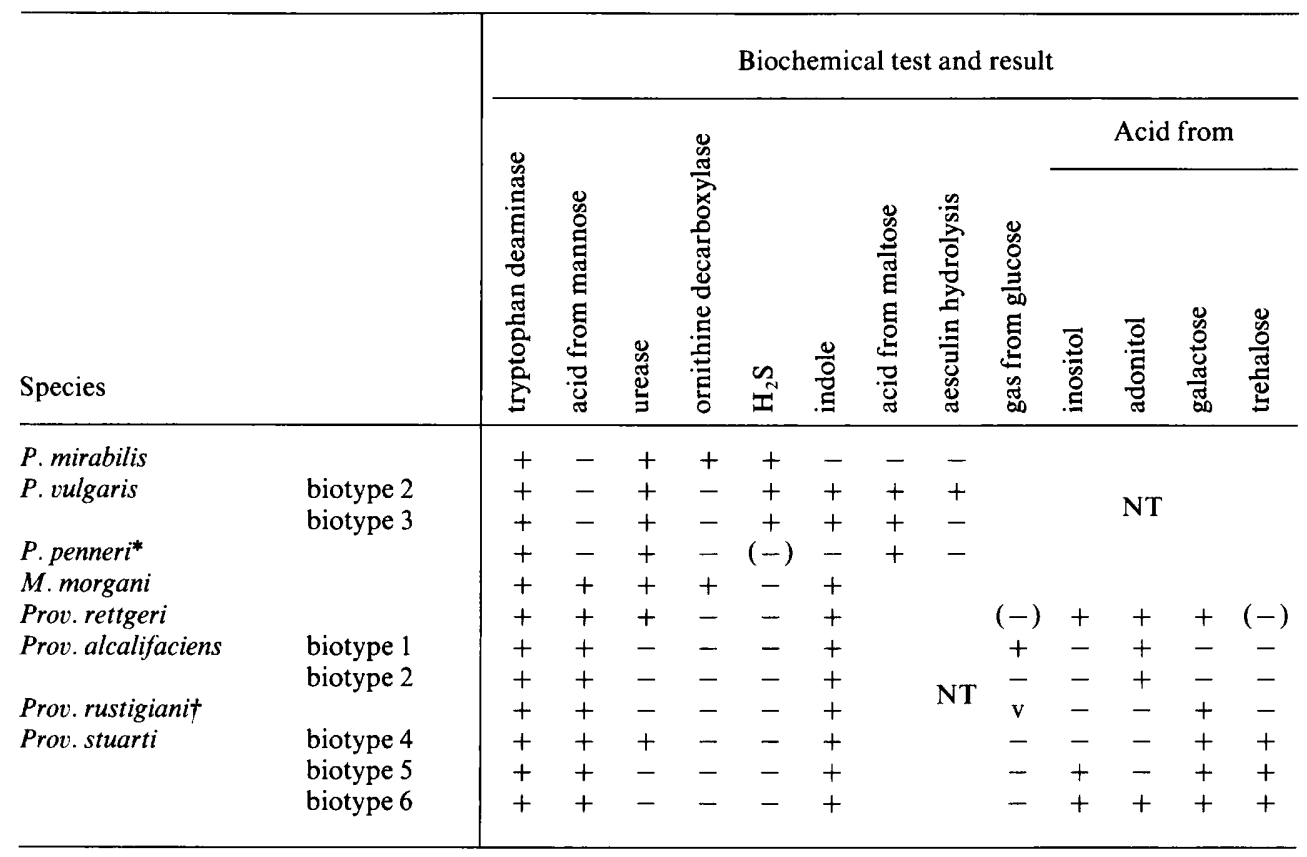

$+=$ Production; $-=$ no production; ()$=$ most strains; $v=$ different strains give different results; NT $=$ not tested.

* Data from Hickman et al. (1982).

† Data from Hickman-Brenner et al. (1983).

protease-producing strains of biotype 3 however was noted.

\section{IgA protease production by $P$. penneri strains}

Five strains of $P$. penneri, each with a unique $\mathbf{P} /$ $S$ type, which had been isolated from faeces of three people with diarrhoea and two healthy people without diarrhoea, were examined. Each strain produced IgA protease.

Lack of detectable IgA protease formation by strains of Morganella and Providencia species

A total of 56 strains was examined for $\operatorname{IgA}$ protease production; 15 were $M$. morgani strains, each with a unique bacteriocine type, isolated from faeces, urine, CSF and wounds of patients with various clinical symptoms; 14 were strains of eight different $\mathrm{O}$-antigenic types of Prov. rettgeri isolated from faeces and urine; 15 were strains of Prov. alcalifaciens isolated from faeces, seven being of biotype 1 and eight of biotype 2; five were strains of Prov. rustigiani isolated from faeces; seven were strains of Prov. stuarti biotype 5 isolated from faeces, urine and a wound. Not one of these 56 strains produced IgA protease.

\section{Characteristics of the IgA proteases of Proteus species}

Polyacrylamide-gel analysis of the products of IgA cleavage by the enzyme from each of the 32 IgA protease producing Proteus strains showed that, regardless of the species, $\mathrm{O}$ antigenicity, biotype or bacteriocin type, the enzyme from each strain cleaved exclusively the IgA heavy chain, to give fragments of mol. wts $\left(10^{3}\right) c .47$ and 34 , and was inhibited by the presence of $5 \mathrm{~mm}$ EDTA. The cleavage products were quite different in size from the IgA heavy chain hinge-cutting proteases of $S$. pneumoniae (inhibited by $5 \mathrm{mM}$ EDTA) and $N$. gonorrhoeae (resistant to $5 \mathrm{mM}$ EDTA) (see figure).

\section{Discussion}

Although $\operatorname{IgA}$ protease production was not detected in any of the 56 diverse strains of Morganella and Providencia species examined, it was commonly found amongst strains of Proteus 


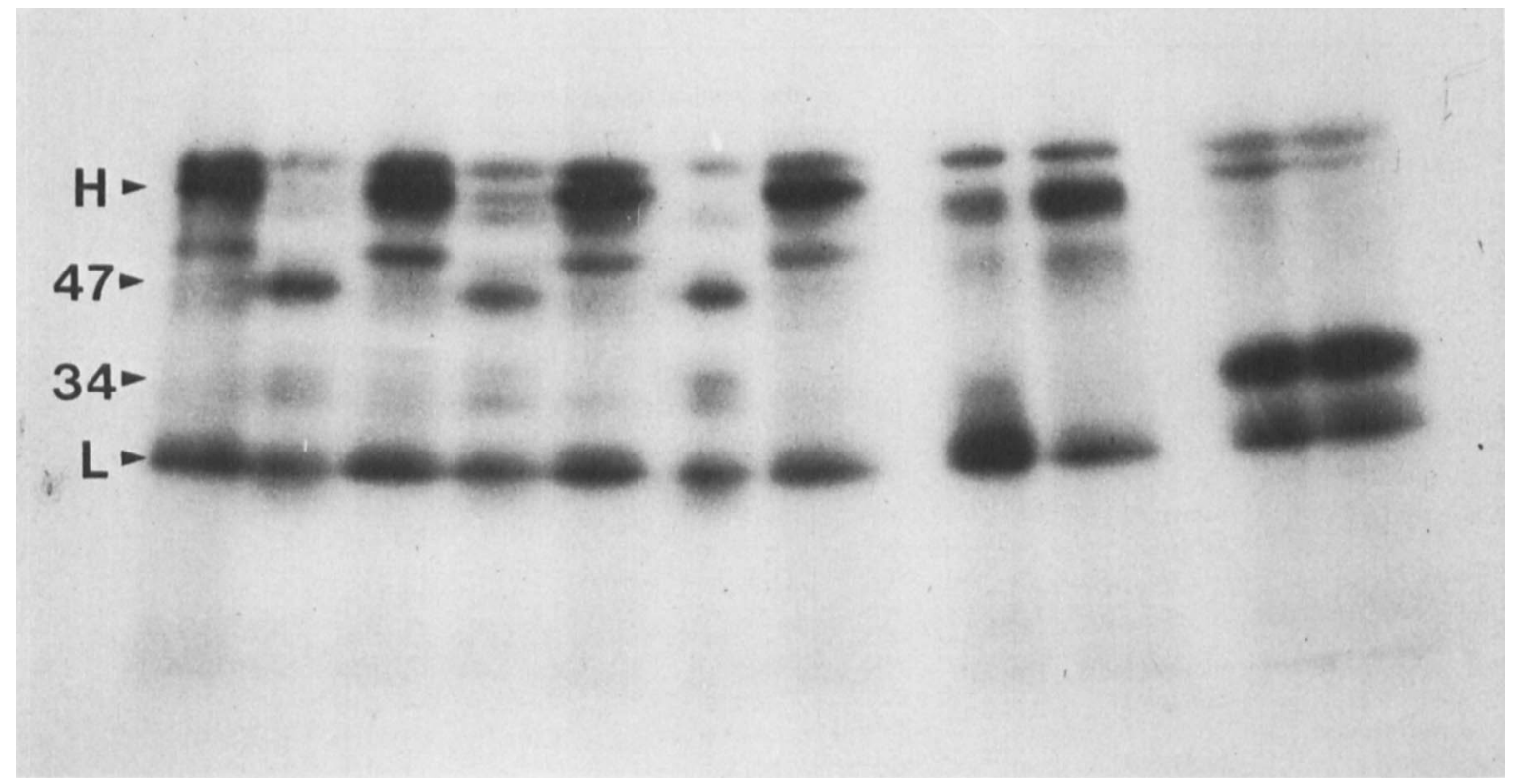

Figure. Polyacrylamide gel analysis of ${ }^{125} \mathrm{I}-\mathrm{IgA}$ digested with various microbial proteases. All the protease enzymes from strains of Proteus spp. were EDTA sensitive and cleaved the IgA heavy chain to fragments of mol. wts $\left(10^{3}\right) 47$ and 34 . Left to right: 1 . Control (untreated IgA); IgA treated with-2. P. mirabilis 64676 protease; 3. (2) with 5 mM EDTA; 4 . P. vulgaris $60694 / 78$ protease; 5. (4) with 5 mM EDTA; 6. P. penneri E1152 protease; 7. (6) with 5 mM EDTA; 8. $S$. pneumoniae protease; 9 . (8) with 5 M EDTA; 10. $N$. gonorrhoeae protease; 11 . (10) with $5 \mathrm{mM}$ EDTA. $\mathrm{H}=$ heavy chain; $\mathrm{L}=$ light chain.

spp. This was particularly true for strains of $P$. mirabilis and $P$. penneri-the enzyme being formed by every strain of these species examined-but true to a lesser extent for strains of $P$. vulgaris of which only $50 \%$ produced IgA protease. There was a significant difference in the frequency of $\operatorname{IgA}$ protease production by $P$. vulgaris strains of biotype 2 compared with those of biotype 3 , but the reason for this is unclear. With this exception, IgA protease production did not appear to be associated with any other characteristic of the producing strain. It was detectable in strains of diverse $\mathrm{O}$ antigenic and bacteriocinogenic types, from various sources, in both sick and healthy individuals.

Our observation that the $\operatorname{IgA}$ protease of $N$. gonorrhoeae was more resistant to inhibition by EDTA than that of $S$. pneumoniae has also been reported by others (Kilian et al., 1983a). This may indicate that the former enzyme is an alkaline metal-dependent protease, whereas the latter enzyme is a neutral metal-dependent protease. Although the IgA proteases of all the Proteus spp. were like the $S$. pneumoniae protease in being inhibited by $5 \mathrm{~mm}$ EDTA, the size of the cleavage products of the IgA heavy chain were quite different from those resulting from cleavage with the $\operatorname{IgA}$ proteases of either S. pneumoniae or $N$. gonorrhoeae, which cut in the hinge region, and of a size indicating cleavage outside the hinge region. The action of IgA proteases of strains of Proteus spp. may, therefore, not be restricted, as are the $\operatorname{IgA}$ proteases of other bacteria, to the immunoglobulins of isotype IgA1. Such a wider activity would clearly be of advantage to an invading Proteus strain seeking to establish infection. We intend to purify the Proteus IgA protease, determine its precise site of cleavage and investigate the activity of the enzyme upon various purified immunoglobulins, including secretory $\operatorname{IgA}$.

We are grateful to Drs O. Ang, P. Hawkey, C. Hughes, P. Larsson, R. Maskell, H. Muller, P. Noone and G. Sweeney for the gift of some of the strains. One of us (MA) acknowledges financial support from the EEC Interdisciplinary Training Grant and from NATO (NATO Science Fellowship) and from the Danish Science Research Council. 


\section{REFERENCES}

Bergström T 1972 Sex differences in childhood urinary tract infection. Archives of Diseases of Childhood 47: 227-232.

Blake M S, Swanson J 1978 Studies on gonococcus infection. XVI. Purification of Neisseria gonorrhoeae immunoglobulin A1 protease. Infection and Immunity 22: 350-358.

Braude A I, Siemienski J, Shapiro A B 1960 The role of bacterial urease in the pathogenesis of pyelonephritis. In: Quinn E L, Kass E $\mathrm{H}$ (eds) Biology of pyelonephritis, Churchill Livingstone, London. pp 69-88.

Fairley K F et al. 1971 Site of infection in acute urinary tract infection in general practice. Lancet 2: 615-618.

Griffith D P, Musher D M, Campbell J W 1973 Inhibition of bacterial urease. Investigative Urology 11 : 234-238.

Hallett R J, Pead L, Maskell R 1976 Urinary infection in boys. A three year prospective study. Lancet 2: 1107-1110.

Hickman F W, Steigerwalt A G, Farmer J J, Brenner D J 1982 Identification of Proteus penneri sp. nov. formerly known as Proteus vulgaris indole negative or as Proteus vulgaris biogroup 1. Journal of Clinical Microbiology 15: 1097-1102.

Hickman-Brenner F W, Farmer J J, Steigerwalt A G, Brenner D J 1983 Providencia rustigianii: a new species in the family Enterobacteriaceae formerly known as Providencia alcalifaciens biogroup 3. Journal of Clinical Microbiology 17: 10571060.

Hunter W M, Greenwood F C 1962 Preparation of Iodine-131 labelled human growth hormone of high specific activity. Nature 194: 495-496.

Khan A J, Ubriani R S, Bombach E, Agbayani M M, Ratner H, Evans H E 1978 Initial urinary tract infection caused by Proteus mirabilis in infancy and childhood. Journal of Pediatrics 93: 791-793.

Kilian M, Mestecky J, Schrohenloher R E 1979 Pathogenic species of the genus Haemophilus and Streptococcus pneumoniae produce immunoglobulin $\mathrm{Al}$ protease. Infection and Immunity 26: 143-149.

Kilian M, Mestecky J, Kulhavy R, Tomana M, Butler W T 1980 IgAl proteases from Haemophilus influenzae, Streptococcus pneumoniae, Neisseria meningitidis and Streptococcus sanguis: comparative immunochemical studies. Journal of Immunology 124: $2596-2600$.

Kilian M, Holmgren K 1981 Ecology and nature of immunoglobulin $\mathrm{Al}$ protease--producing streptococci in the human oral cavity and pharynx. Infection and Immunity 31 : 868 873.

Kilian M 1981 Degradation of immunoglobulins A1, A2 and G by suspected principal periodontal pathogens. Infection and Immunity 34: 757-765.
Kilian M, Thomsen B, Petersen T E, Bleeg H S $1983 a$ Occurrence and nature of bacterial IgA proteases. Annals of the New York Academy of Sciences 409: 612-624.

Kilian M, Thomsen B, Petersen T E, Bleeg H $1983 b$ Molecular biology of Haemophilus influenzae IgAl proteases. Molecular Immunology 20: 1051-1058.

Male C J 1979 Immunoglobulin Al protease production by Haemophilus influenzae and Streptococcus pneumoniae. Infection and Immunity 26 : 254-261.

Mulks M H, Plaut A G 1978 IgA protease production as a characteristic distinguishing pathogenic from harmless Neisseriaceae. New England Journal of Medicine 299: 973976.

Mulks M H, Kornfeld S J, Plaut A G 1980a Specific proteolysis of human IgA by Streptococcus pneumoniae and Haemophilus influenzae. Journal of Infectious Diseases 141: 450-456.

Mulks M H, Plaut A G, Feldman H A, Frangione B $1980 b$ IgA proteases of two distinct specificities are released by Neisseria meningitidis. Journal of Experimental Medicine 152: $1442-1447$

Plaut A G, Genco R J, Tomasi T B 1974 Isolation of an enzyme from Streptococcus sanguis which specifically cleaves IgA. Journal of Immunology 113: 289-291.

Plaut A G, Gilbert J V, Artenstein M S, Capra J D 1975 Neisseria gonorrhoeae and Neisseria meningitidis: extracellular enzyme cleaves human immunoglobulin A. Science 190: $1103-1105$.

Senior B W 1977 Typing of Proteus strains by proticine production and sensitivity. Journal of Medical Microbiology 10: $7-17$

Senior B W 1979 The special affinity of particular types of Proteus mirabilis for the urinary tract. Journal of Medical Microbiology 12 : 1-8.

Senior B W 1987 The typing of Morganella morgani by bacteriocin production and sensitivity. Journal of Medical Microbiology 23: 33-39.

Senior B W, Larsson P 1983 A highly discriminatory multityping scheme for Proteus mirabilis and Proteus vulgaris. Journal of Medical Microbiology 16: 193-202.

Senior B W, Leslie D L 1986 Rare occurrence of Proteus vulgaris in faeces: a reason for its rare association with urinary tract infections. Journal of Medical Microbiology 21 : 139-144.

Senior B W, Albrechtsen M, Kerr M A 1987 Proteus mirabilis strains of diverse type have IgA protease activity. Journal of Medical Microbiology 24: 175-180.

Young H 1978 Identification and penicillinase testing of Neisseria gonorrhoeae from primary isolation cultures on modified New York City medium. Journal of Clinical Microbiology 7: 247-250. 